\title{
Outer envelope membranes from chloroplasts are isolated as right-side-out vesicles
}

\author{
Karin Waegemann ${ }^{1}$, Susanne Eichacker ${ }^{2}$, and Jürgen Soll ${ }^{1 *}$ \\ 1 Botanisches Institut, Universität Kiel, Olshausenstrasse 40, W-2300 Kiel, Federal Republic of Germany \\ 2 Botanisches Institut, Universität München, Menzinger Strasse 67, W-8000 München 19, Federal Republic of Germany
}

Received 5 September; accepted 16 December 1991

\begin{abstract}
Outer envelope membranes were isolated from purified chloroplasts of pea leaves. The sidedness of the vesicles was analyzed by (i) aqueous polymer-two phase partitioning, (ii) the effect of limited proteolysis on the outer-envelope proteins (OEP) 86 and OEP 7 in intact organelles and isolated membranes, (iii) fluorescencemicroscopy and finally (iv) binding of precursor polypeptides to isolated outer-membrane vesicles. The results demonstrate that purified outer envelope membranes occur largely $(>90 \%)$ as right-side-out vesicles.
\end{abstract}

Key words: Chloroplast (outer envelope membrane) Membrane orientation - Pisum (chloroplasts) - Vesicle sidedness

\section{Introduction}

The purification and separation of inner and outer envelope membranes from chloroplasts (Cline et al. 1981; Block et al. 1983a) made it possible to assign specific functions to each membrane fraction (for a review, see Douce et al. 1984). The inner envelope membrane is active in, for example, galactolipid (Block et al. 1983b) and prenyllipid metabolism (Soll 1987) as well as in the transport of low-molecular-weight substances via specific carrier proteins, e.g. the phosphate-triosephosphate translocator (Flügge and Heldt 1981). The outer envelope membrane is in contact with the cytoplasm and one of its prominent functions is the recognition of nuclear-encoded precursor proteins destined for the chloroplast (Keegstra et al. 1989). Receptor-mediated binding of biomolecules or transport events are best studied with

\footnotetext{
* To whom correspondence should be addressed

Abbreviations: $\mathrm{FITC}=$ fluorescein isothiocyanate; IEP $=$ inner-envelope protein; $\mathrm{OEP}=$ outer-envelope protein; $\mathrm{pSSU}=$ precursor form of the small subunit of ribulose bisphosphate carboxylaseoxygenase; SDS-PAGE = sodium dodecyl sulfate-polyacrylamide gel electrophoresis
}

membrane vesicles of known orientation, i.e. right-sideout or inside-out. The availability of outer-envelope membrane vesicles with known orientation also allows studies on the arrangement of polypeptide constituents of this membrane.

In this study we report that outer envelope membranes, isolated as in Keegstra and Youssif (1986) occur as right-side-out vesicles, i.e. the cytosolic side of the membrane is exposed at the surface of the vesicle.

\section{Material and methods}

Purification of chloroplast outer envelope membranes. Chloroplasts were purified from the leaves of two-weak-old pea (Pisum sativum L., cv. Golf, Bayerische Futtersaatbau, München, FRG) plants grown in the field by standard procedures (Nakatani and Barber 1977). Percoll-purified organelles equivalent to $150 \mathrm{mg}$ of chlorophyll (Chl; Arnon 1949) were treated hypertonically in $0.65 \mathrm{M}$ sucrose, $10 \mathrm{mM} \mathrm{N}$-[tris(hydroxymethyl)-methyl]-glycine (Tricine)-KOH (pH 7.9) for $10 \mathrm{~min}$ on ice (final $\mathrm{Chl}$ concentration about 2 $\mathrm{mg} \cdot \mathrm{ml}^{-1}$ ). Chloroplasts were ruptured by 30 strokes in a dounce homogenizer (Kontes Instr., Vineland, N.Y., USA) with a tightfitting pestle (Keegstra and Youssif 1986). The solution was diluted twofold by $10 \mathrm{mM}$ Tricine- $\mathrm{KOH}(\mathrm{pH} \mathrm{7.9)}$ and the majority of unbroken chloroplasts and thylakoids removed by a low-speed centrifugation $(6250 \cdot g, 10 \mathrm{~min})$. The greenish supernatant was recovered and, after another twofold dilution, a crude envelope pellet was obtained by centrifugation at $150000 \cdot g$ for $1 \mathrm{~h}$. The viscous upper layer of the pellet, consisting mostly of outer membranes, was recovered separately. The final pellet was resuspended in $10 \mathrm{mM}$ Tricine ( $\mathrm{pH}$ 7.9). Both suspensions were layered on top of discontinuous sucrose density gradients consisting of $10 \mathrm{ml}$ each of $0.996 \mathrm{M}, 0.8 \mathrm{M}$ and $0.4 \mathrm{M}$ sucrose in $10 \mathrm{mM}$ Tricine (pH 7.9). After centrifugation for $16 \mathrm{~h}$ at $125000 \cdot \mathrm{g}$, separated membranes were recovered from the gradient, diluted fourfold and pelleted for $90 \mathrm{~min}$ at $125000 \cdot \mathrm{g}$. Membranes were resuspended at a protein concentration of $5 \mathrm{mg} \cdot \mathrm{ml}^{-1}$ (Lowry et al. 1951) and stored in liquid $\mathrm{N}_{2}$. About ten preparations were pooled and purified again on continuous sucrose density gradients $(0.6-1.2 \mathrm{M}$ sucrose; $2 \mathrm{mM}$ EDTA; $10 \mathrm{mM} \mathrm{Na}_{3} \mathrm{PO}_{4}, \mathrm{pH} 7.4 ; 125000 \cdot \mathrm{g}$ for $16 \mathrm{~h}$ ). The gradient was fractionated manually from the top. Membranes were recovered after fourfold dilution by centrifugation as above and stored in liquid $\mathrm{N}_{2}$. 
Protease treatment. Intact purified chloroplasts were treated with thermolysin (Boehringer, Mannheim, FRG) at $200 \mu \mathrm{g} \cdot(\mathrm{mg} \mathrm{Chl})^{-1}$ for $30 \mathrm{~min}$ on ice (Cline et al. 1984). The reaction was stopped by the addition of excess EDTA. Intact organelles were repurified through Percoll gradients. Envelope membranes were purified from these organelles as above. Envelope membranes were treated with thermolysin at $0.1 \mu \mathrm{g}$ thermolysin $\cdot \mu \mathrm{g}^{-1}$ membrane protein for 20 min on ice. The reaction was terminated as above and membranes recovered by centrifugation $(250000 \cdot g, 20 \mathrm{~min})$.

Immunological analysis. Antibodies were raised in rabbits against a synthetic peptide, identical to the C-terminal 15 amino acids of OEP 7 (Salomon et al. 1990). The peptide was coupled to rabbit serum albumin by glutaraldehyde prior to immunisation of the rabbit (Harlow and Lane 1988, pp. 77-79). Agglutination of intact chloroplasts by antibodies directed against the C-terminus of OEP 7 was done in $330 \mathrm{mM}$ sorbitol, $50 \mathrm{mM}$ 4-(2-hydroxyethyl)-1-piperazine ethanesulfonic acid (Hepes)- $\mathrm{KOH}(\mathrm{pH} \mathrm{7.6)}$ (buffer A) at $100 \mu \mathrm{g}$ $\mathrm{Chl} \cdot \mathrm{ml}^{-1}$ for $5 \mathrm{~min}$ at $25^{\circ} \mathrm{C}$ (Joyard et al. 1983). In some cases the antibody solution was pretreated with a synthetic peptide $(25 \mu \mathrm{g})$ identical to the C-terminus of OEP 7.

Immunfluorescence labelling of intact organelles with OEP 7-peptide-specific antibodies was done as in Joyard et al. (1983). Intact chloroplasts were incubated in $1 \mathrm{ml}$ buffer $\mathrm{A}$ and $2 \mu \mathrm{l}$ antiserum at a final Chl concentration of $0.1 \mathrm{mg} \cdot \mathrm{ml}^{-1}$ for $30 \mathrm{~min}$ on ice. Chloroplasts were recovered by centrifugation and washed twice in buffer A. Fluorescein isothiocyanate (FITC)-labelled secondary antibodies (Sigma Chemicals, München, FRG) were incubated with the washed organelles for $30 \mathrm{~min}$ on ice in buffer $A$ with the addition of $2.3 \%(\mathrm{w} / \mathrm{v})$ 1,4-diazabicyclooctan (DABCO). Chloroplasts were recovered by centrifugation and washed twice in buffer $\mathrm{A} / 2.3 \%$ DABCO. The organelles were resuspended in $10 \mu \mathrm{l}$ buffer $\mathrm{A} / 2.3 \%$ DABCO. Microscopy was done using a Zeiss Photomicroscope III equipped with a special FITC-filter set (Nr. 487709, Zeiss, Oberkochen, FRG) supplemented with a red-free filter (KP 560) in order to suppress autofiuorescence of the chloroplasts.

Western-blot analysis was carried out as described by Towbin et al. (1979).

Precursor binding. The precursor form (pSSU) of the small subunit of ribulose bisphosphate carboxylase-oxygenase (EC4.1.1.39) was used. The protein was synthesized in an in vitro transcriptiontranslation system in the presence of $\left[{ }^{35}\right.$ S]methionine (Salomon et al. 1990). The cDNA clone used is described in Lubben and Keegstra (1986). Binding of pSSU was carried out at $100 \mu \mathrm{M}$ ATP, $3 \mathrm{mM}$ $\mathrm{MgCl}_{2}$ in buffer $\mathrm{A}$ for $10 \mathrm{~min}$ at room temperature using $10 \mu \mathrm{g}$ of envelope protein. Membranes were recovered by centrifugation and washed once (Waegemann and Soll 1991) prior to sodium dodecyl sulfate-polyacrylamide gel electrophoresis (SDS-PAGE) (Laemmli 1970) and fluorography (Bonner and Laskey 1974).

Phase-partitioning of outer envelope membranes (Albertsson et al. 1982). Phase-partitioning was carried out in $6 \%(\mathrm{w} / \mathrm{w})$ dextran (T500; Pharmacia, Uppsala, Sweden), 6\% (w/w) polyethylene glycol (PEG 3350; Union Carbide, New York, USA) in the presence of $5 \mathrm{mM} \mathrm{NaCl}, 20 \mathrm{mM}$ sucrose and $10 \mathrm{mM} \mathrm{Na}_{3} \mathrm{PO}_{4}$ buffer $(\mathrm{pH} \mathrm{7.6)}$. The mixture was cooled to $3-4^{\circ} \mathrm{C}$ before envelope membranes $(270 \mu \mathrm{g})$ were added in $100 \mu \mathrm{l} \mathrm{Na} \mathrm{PO}_{4}$ buffer $(\mathrm{pH} 7.4)$. The final size of the transfer system was $2.5 \mathrm{~g}$. The slurry was vortexed for $20 \mathrm{~s}$ and subsequently centrifuged for $45 \mathrm{~s}$ at $660 \cdot \mathrm{g}$ in a swinging-bucket rotor to obtain phase separation (partition I). Top and bottom phases were transferred separately to new bottom (A) and top (B) phases, respectively, mixed and centrifuged as above (partition IIA, IIB). Then the upper phase from IIA was moved to a fresh bottom phase (partition IIIA) and the bottom phase from IIB received a fresh upper phase (partition IIIB). The top phase from IIB was transferred to the bottom phase from IIA (partition IIIC). The three phase-systems were treated as above. The partitions IIIA-C repre- sent tubes 1-3 in Fig. 1A, respectively. Both phases of each tube were diluted twofold in $\mathrm{Na}_{3} \mathrm{PO}_{4}$ buffer, $5 \mathrm{mM} \mathrm{MgCl}$ and membranes recovered by centrifugation $(250000 \cdot \mathrm{g}, 20 \mathrm{~min}$ ). Membranes were resuspended in $\mathrm{Na}_{3} \mathrm{PO}_{4}$ buffer and used for further analysis.
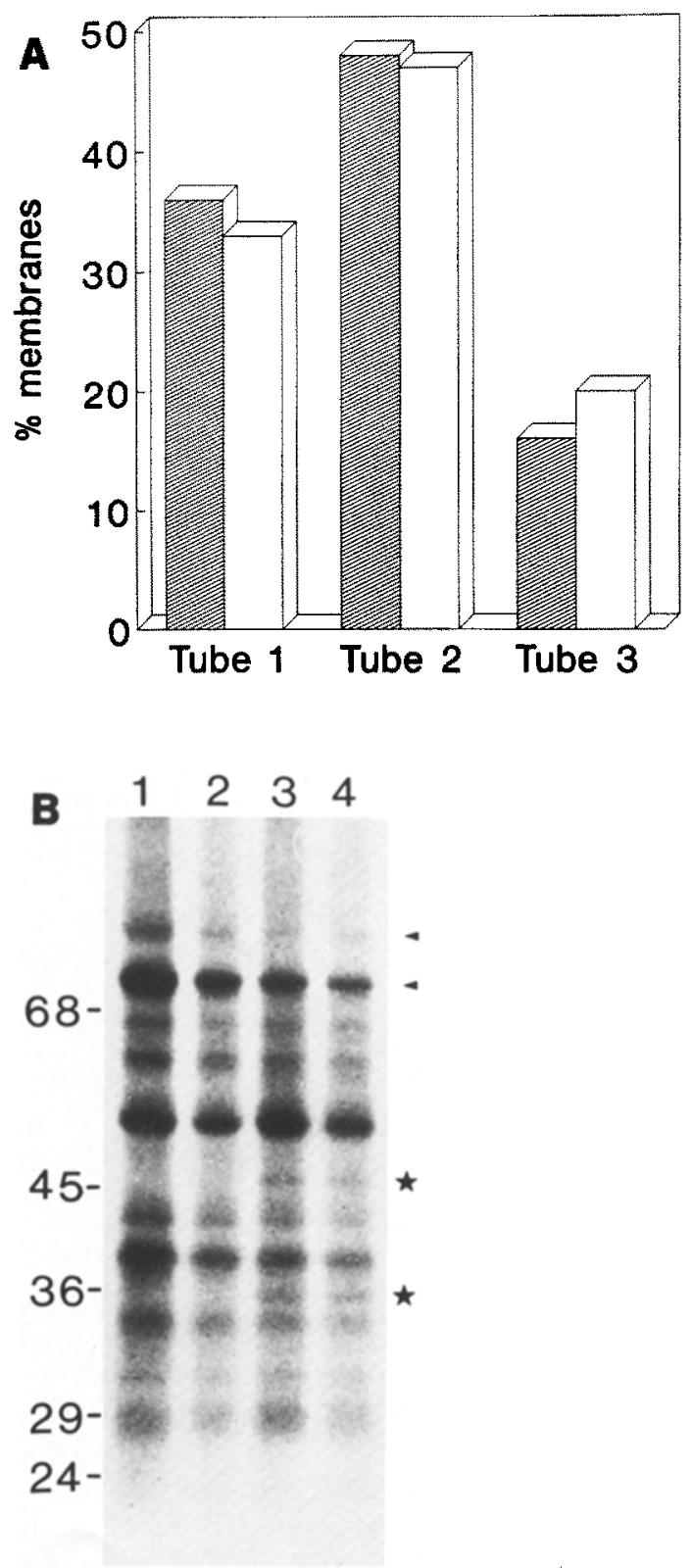

Fig. 1A, B. The behaviour of the outer envelope of pea chloroplasts in an aqueous two phase-system after two transfer-reactions. A The contents of tubes 1-3 were collected by centrifugation and the protein contents (D) estimated by the method of Lowry et al. (1951). As a comparison the theoretical distribution of a homogeneous suspension following a 6:4 (top:bottom) distribution (8) is shown. B Outer envelope membranes recovered from the top or bottom phase of tube 3 were phosphorylated by $\gamma$-[32P]ATP (lanes 1, 2, respectively). Aliquots of each of these membranes were subsequently treated with thermolysin for 1 min (lanes 3,4 ). The aster isks indicate proteolytic breakdown products, the arrowheads, ${ }^{32} \mathrm{P}$. labelled polypeptides which are degraded by thermolysin. An autoradiogram of proteins separated by SDS-PAGE is shown. Numbers on the left indicate molecular markers in $\mathrm{kDa}$ 

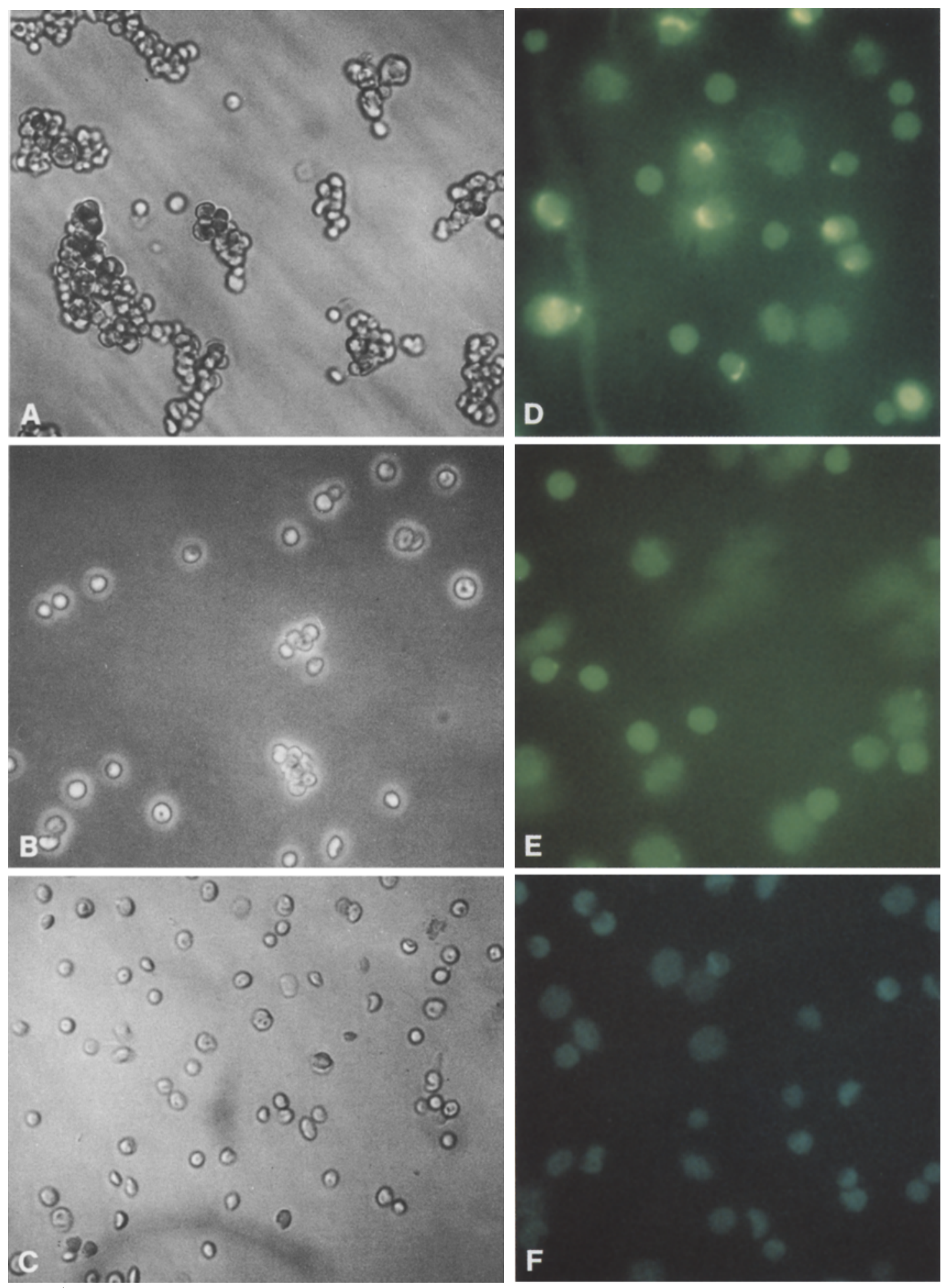

Fig. 2A-F. The C-terminus of OEP 7 is exposed to the cytosolic leaflet of the outer envelope. Experiments were carried out with intact chloroplasts using an antibody directed against the C-terminal 15 amino acids of OEP 7. A Agglutination of chloroplasts (1:50 antibody dilution); $\mathbf{B}$ as $\mathbf{A}$ but in the presence of $25 \mu \mathrm{g}$ synthetic

\section{Results}

We analysed the behaviour of outer-envelope membrane vesicles in an aqueous two-phase system containing polyethylene glycol and dextran. After the initial partitioning peptide of the OEP 7 C-terminus; $\mathbf{C}$ as $\mathbf{A}$ but pre-immune serum was used; $\mathbf{D}$ immunofluorescence using the peptide-specific antibody (dilution 1:500); $\mathbf{E}$ as $\mathbf{D}$ but chloroplasts were treated with thermolysin prior to antibody labelling; F as D but pre-immune serum was used

reaction the top and bottom phases were each subjected to two additional transfer reactions. The membrane material was enriched in tube two as determined by the protein content (Fig. 1A). The partitioning of envelope membranes between the two phases corresponded well to 
that of a homogeneous vesicle population (Fig. 1A), which follows a 6:4 (top: bottom) distribution (Albertsson 1971). It was not possible to carry out more transfer steps because the membrane vesicles disintegrated after prolonged exposure to polyethylene glycol and dextran. Membranes recovered from either the top or bottom phase showed the same polypeptide composition when analysed by SDS-PAGE and silver staining of the gel (data not shown). Membranes recovered from top and bottom phases, respectively, were incubated in the presence of $\gamma-\left[{ }^{32} \mathrm{P}\right]-A T P$ as in Soll et al. (1989). The phosphorylation pattern of envelope proteins was identical in both membrane pools (Fig. 1B, lanes 1, 2). Furthermore, when such phosphorylated envelope membrane vesicles were treated with thermolysin, identical phosphorylated proteolytic peptides were detected (Fig. 1B, lanes 3,4$)$. Chymotrypsin treatment of membrane vesicles recovered from either the top or bottom phase also resulted in an identical pattern of proteolytic breakdown products, as determined by SDS-PAGE and silver staining (not shown). These results (Fig. 1A, B) indicate a largely homogeneous composition or sidedness of the isolated outer-envelope vesicles.

To gain further information about the sidedness of isolated outer-envelope vesicles we compared their properties to those of outer envelopes in situ, i.e. in intact chloroplasts. Outer-envelope protein 7 is a marker protein of the outer envelope membrane (Joyard et al. 1983).

Initial evidence indicated that the C-terminus is exposed on the cytosolic leaflet of the outer envelope membrane (Salomon et al. 1990) and is susceptible to protease treatment. For this study we raised polyclonal antibodies in a rabbit against a synthetic peptide identical to the C-terminal 15 amino acids of OEP 7 . The antiserum was able to recognize the C-terminal part of OEP 7 in intact chloroplasts and thus led to their agglutination (Fig. 2A). When the assay was carried out in the presence of the synthetic C-terminal peptide of OEP 7, agglutination of the chloroplasts was greatly diminished (Fig. 2B). Preimmune serum was without effect (Fig. 2C). These results were corroborated by immunofluorescence microscopy using the peptide-specific antibody as primary label and FITC-conjugated anti-rabbit immunoglobulin $\mathrm{G}$ (IgG) as secondary label. Chloroplasts which were decorated with the antibodies fluoresced in bright light after incubation with FITC-labelled anti-rabbit IgG (Fig. 2D). Thermolysin treatment of the intact organelles prior to the antibody incubation resulted in an almost complete loss of the immune reactivity (Fig. 2E). When preimmune serum was used in the experimental regime no FITC label was observed at the organellar surface (Fig. 2F). The data demonstrate that the antigenic part i.e. the C-terminus of OEP 7 was removed by the protease. Agglutination of chloroplasts is not observed in these experiments because the antiserum is used at a 10 -fold higher dilution. The autofluorescence of chloroplasts was suppressed by a special filter (see Material and methods). The results described above clearly establish the localization of the C-terminus of OEP 7 to the cytosolic leaflet of outer envelope membranes from chloroplasts.

Only surface-exposed polypeptides were degraded by

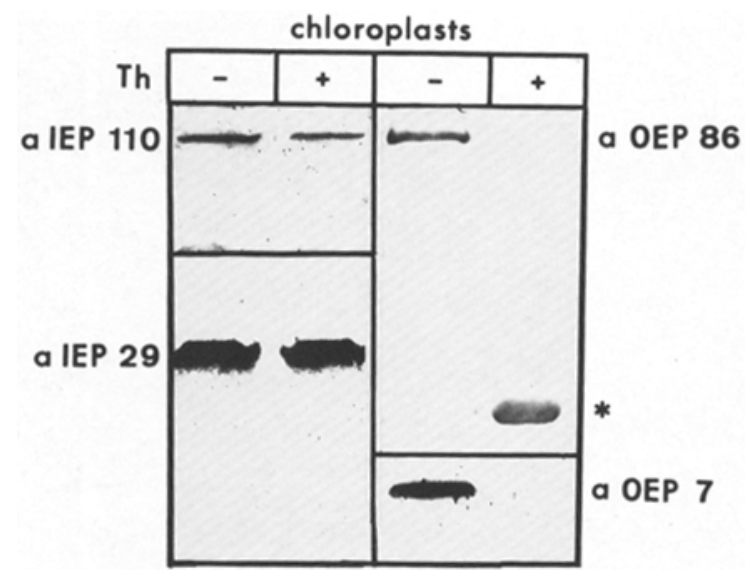

Fig. 3. Thermolysin proteolytically cleaves only outer-envelope polypeptides but not inner ones in intact chloroplasts. Chloroplasts were either treated or not treated with thermolysin $(T h)$ and then assayed by Western-blot analysis using antibodies against innerenvelope marker proteins of $110 \mathrm{kDa}$ and $29 \mathrm{kDa}$ (a IEP II0, a IEP 29 left panel) and the outer-envelope proteins of $86 \mathrm{kDa}$ and $7 \mathrm{kDa}$ (a OEP 86, a OEP 7 right panel). The asterisk marks the proteolytic breakdown product of OEP 86. Four separate Western blots are shown

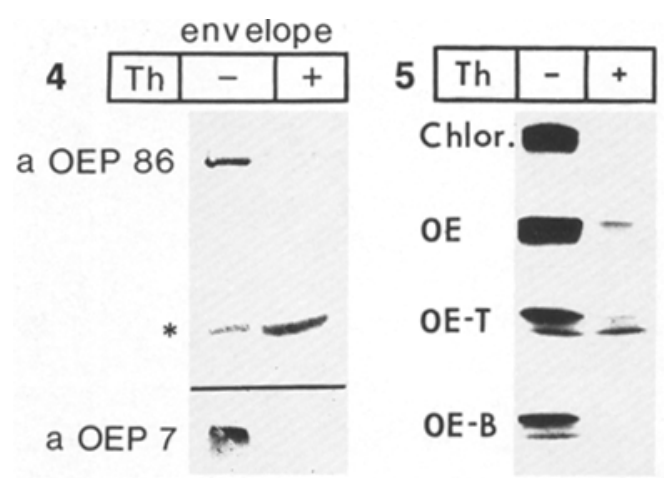

Fig. 4. Protease treatment of isolated outer envelope membranes yields results identical to those for intact chloroplasts. Outer envelope membranes were either treated or not treated with thermolysin $(T h)$. They were subsequently analysed by SDS-PAGE and immunoblotting using antibodies. The asterisk denotes the OEP 86 breakdown product as in Fig. 3

Fig. 5. Binding of precursor polypeptides to intact chloroplasts and the outer envelope is dependent on protease-sensitive components. Chloroplasts (Chlor) and outer envelope $(O E)$ were treated with thermolysin $(T h)$, repurified and incubated with ${ }^{35}$ S-labelled pSSU. Outer envelope membranes were distributed in an aqueous twophase system by two transfer reactions (as described in Material and methods). The membranes recovered from either the top $(O E-T)$ or bottom $(O E-B)$ phase of tube 1 were either treated or not treated with thermolysin as indicated, and subsequently incubated with pSSU

thermolysin treatment under the conditions applied. Inner-envelope proteins (IEPs), e.g. IEP 110, and IEP 29 were not proteolytically degraded (Fig. 3). Thermolysin treatment of intact organelles resulted in the degradation of OEP 86 and the concomittant occurrence of a protease-resistant proteolytic fragment which was still detectable by Western-blot analysis (Fig. 3). Under these conditions the C-terminus of OEP 7 was cleaved off, and 
the proteolytic breakdown product was no longer recognized by the antibody specific for the C-terminus (Fig. 3). The residual membrane-spanning $\mathrm{N}$-terminal part of OEP 7 is detectable by SDS-PAGE (Joyard et al. 1983; Salomon et al. 1990). If isolated outer-envelope membrane vesicles occur in the same orientation as in intact organelles, i.e. right-side-out, limited proteolysis of envelope membranes should give identical results to those presented for intact chloroplasts in Figs. 2 and 3. This was indeed found to be the case (Fig. 4). Thermolysin treatment of isolated outer envelopes followed by SDSPAGE and immunoblot analysis demonstrated that OEP 86 was protease-sensitive as in the organellar system. A proteolytic breakdown product of molecular size (about $52 \mathrm{kDa}$ ) identical to that demonstrated for chloroplasts was detected in the membrane fraction (Fig. 3). Even before treatment with thermolysin low amounts of the OEP 86 breakdown product were detectable in purified outer envelope membranes, probably as a consequence of endogenous protease activity during the long purification procedure (compare Fig. 4). The immunoreactivity of thermolysin-treated outer-envelope vesicles to OEP 7 antibodies was completely lost (Fig. 4), demonstrating that the $\mathrm{C}$-terminal portion of OEP 7 was removed by the protease, i.e. the $\mathrm{C}$-terminus was exposed to the outside of the vesicle (compare Fig. 2). The protease treatment of outer-envelope membrane vesicles would not have resulted in a complete loss of immune response to the antibody specific to the OEP 7 $\mathrm{C}$-terminus if inside-out vesicles had been present in the vesicle population to any appreciable extent $(>5 \%)$.

One of the major functions of the outer chloroplast envelope is the recognition of precursor polypeptides destined for the inside of the organelle. Protease-sensitive receptor polypeptides initiate the translocation event (Keegstra et al. 1989). When intact chloroplasts were treated with thermolysin, the capacity of precursor protein binding was greatly diminished (Fig. 5, lanes a, b). Outer envelope membranes were also able to bind precursor proteins in a receptor-dependant manner. As in the intact organelle, digestion of the outer membrane with protease abolished precursor binding almost completely, indicating that outer envelope membranes are isolated as outside-out vesicles. Envelope membranes separated by phase-partitioning and recovered from top and bottom phases, respectively, were also analysed for their capacity to bind pSSU. Membranes recovered from either phase showed protease-susceptible binding capacity. The data corroborate the results presented in Fig. 1 which indicated that the isolated outer membranes represent a vesicle population of largely homogenous orientation.

\section{Discussion}

Outer and inner envelope membranes can be forced apart by hypertonic treatment of the intact organelle. If the chloroplasts are then subjected to shearing forces by either passage through a Yeda Press (Block et al. 1983a) or a dounce homogenizer (Keegstra and Youssif 1986), membrane fragments become detached from the organelles and then reseal to form vesicles (Cline et al. 1985) which can be purified by sucrose density gradients. In order to study the topology of envelope proteins or their function as receptor polypeptides and carrier proteins in the purified membrane system, it is important to know the orientation of the isolated vesicle population. In the present study we used different approaches to determine the sidedness of purified outer envelope membranes from chloroplasts. Aqueous two-phase partitioning, which has been successfully applied to separate thylakoid membranes (Andersson 1986) or plasma membranes (Larsson et al. 1984) into inside-out and rightside-out vesicles, was also used here to analyze the sidedness of isolated outer envelopes.

The results obtained with this method and further experiments indicated a largely homogeneous orientation of the envelope vesicles analyzed. Further experiments were conducted to determine the sidedness, i.e. right-side-out or inside-out, of outer envelope vesicles. Here we took advantage of the fact that we were able to compare the properties of outer envelope membranes in situ, i.e. right-side-out in intact chloroplasts, with the properties of the isolated vesicles in vitro. Thermolysin, a protease which does not penetrate the outer membrane, was used to digest surface exposed membrane proteins (Joyard et al. 1983; Cline et al. 1984). In combination with immunological analysis, using antibodies against the outer-envelope marker proteins OEP 86 and OEP 7 , it became evident that isolated outer envelopes gave results identical to those for intact chloroplasts. The C-terminus of OEP 7 was almost completely removed by thermolysin treatment of outer envelope vesicles. In addition, OEP 86 was proteolytically cleaved and a membrane-bound breakdown product detected at a lower molecular weight in both systems. Only minor amounts of OEP 86 and OEP 7 were not accessible to thermolysin treatment in isolated envelope membrane vesicles (see Fig. 4) and could thus be present in inside-out vesicles. Considering the technical limitations of the systems applied we estimate that more than $90 \%$ of isolated outer envelope vesicles are oriented right-side-out.

The outer chloroplast envelope forms the barrier between the organelle and the cytosol. Low-molecularweight substances $(<10000 \mathrm{Da})$ can pass rather freely via porin-like proteins through the outer envelope (Flügge and Benz 1984). Larger molecules such as precursor proteins destined for the inside of the organelle are recognized on the surface (cytosolic leaflet) of the outer envelope by specific receptors and translocated inside the plastid by a multiprotein complex (Waegemann and Soll 1991). Precursor-protein binding capacity is proteasesensitive not only in chloroplasts but also in isolated outer envelopes and membranes obtained from either top or bottom phase of the aqueous two-phase polymer system. This indicates that isolated outer envelopes are outside-out oriented and that top and bottom phases contain equally oriented types of vesicles. In addition, when chloroplasts and isolated outer envelope membranes were incubated with pSSU under conditions which allowed binding but not import, identical trans- 
location intermediates could be detected in both systems after protease treatment (Waegemann and Soll 1991). This should only be possible if the sidedness of outer envelope membranes is identical in vitro, i.e. isolated, to that occuring in situ, i.e. in intact chloroplasts. The results presented here will facilitate further studies on the topology of envelope proteins and directed membrane processes.

We thank P. $\AA$. Albertsson, Lund, Sweden, for introducing one of us (S. E.) to the technique of phase partitioning. This work was supported by the Deutsche Forschungsgemeinschaft (SFB 246) and Fonds der Chemischen Industrie.

\section{References}

Albertsson, P. $-\AA$. (1971) Partition of cell particles and makro molecules, Wiley, New York

Albertsson, P.-A., Andersson, B., Larsson, C., Akerlund, H.-E. (1982) Phase-partition - A method for purification and analysis of cell organelles and membrane vesicles. Methods Biochem. Anal. 28, 115-150

Andersson, B. (1986) Characterization of the thylakoid membrane by subfractionation analysis. Methods Enzymol. 118, 325-338

Arnon, D.J. (1949) Copper enzymes in isolated chloroplasts. Polyphenoloxidase in Beta vulgaris. Plant Physiol. 24, 1-15

Block, M.A., Dorne, A.-J., Joyard, J., Douce, R. (1983a) Preparation and characterization of membrane fractions enriched in outer and inner envelope membranes from spinach chloroplasts. J. Biol. Chem. 258, 13273-13280

Block, M.A., Dorne, A.-J., Joyard, J., Douce, R. (1983b) Preparation and characterization of membrane fractions enriched in outer and inner envelope membranes from spinach chloroplasts. J. Biol. Chem. 258, 13281-13286

Bonner, W.M., Laskey, R.A. (1974) A film detection method for tritium labelled proteins and nucleic acids in polyacrylamide gels. Eur. J. Biochem. 46, 83-88

Cline, K., Andrews, J., Mersey, B., Newcomb, B.H., Keegstra, K. (1981) Separation and characterization of inner and outer envelope membranes of pea chloroplasts. Proc. Natl. Acad. Sci. USA 78, 3595-3999

Cline, K., Werner-Washburne, M., Andrews, J., Keegstra, K. (1984) Thermolysin is a suitable protease for probing the surface of intact pea chloroplasts. Plant Physiol. 75, 675-678

Cline, K., Keegstra, K., Staehelin, L.A. (1985) Freeze fracture electron microscopic analysis of ultrarapidly frozen envelope membranes on intact chloroplasts and after purification. Protoplasma 125, 111-123
Douce, R., Block, M.A., Dorne, A.J., Joyard, J. (1984) The plastid envelope membranes: their structure, composition and role in chloroplast biogenesis. Subcell. Biochem. 10, 1-84

Flügge, U.-I., Benz, R. (1984) Pore forming activity in the outer membrane of the chloroplast envelope. FEBS Lett. 169, 85-89

Flügge, U.-I., Heldt, H.W. (1981) The phosphate translocator of the chloroplast envelope: isolation of the carrier protein and reconstitution of transport. Biochim. Biophys. Acta 638, 296-304

Harlow, E., Lane, D. (1988) Antibodies: A Laboratory Manual. Cold Spring Harbor Laboratory

Joyard, J., Billecocq, A., Bartlett, S. G., Block, M. A., Chua, N. H., Douce, R. (1983) Localization of polypeptides to the cytosolic side of the outer envelope membrane of spinach chloroplasts. J. Biol. Chem. 258, 10000-10006

Keegstra, K., Youssif, A.E. (1986) Isolation and characterization of chloroplast envelope membranes. Methods Enzymol. 118, 316-325

Keegstra, K., Olsen, L.J., Theg, S.M. (1989) Chloroplastic precursors and their transport across the envelope membranes. Annu. Rev. Plant Physiol. 40, 471-501

Laemmli, U.K. (1970) Cleavage of structural proteins during the assembly of the head of bacteriophage T 4. Nature 227, 680-685

Larsson, C., Kjellbohm, P., Widell, S., Lundberg, T. (1984) Sidedness of plant plasma membrane vesicles purified by partitioning in aqueous two phase systems. FEBS Lett. 171, 271-276

Lowry, O.H., Rosebrough, N.J., Farr, A.L., Randall, R.J. (1951) Protein measurement with the folin phenol reagent. J. Biol. Chem. 193, 265-275

Lubben, T.H., Keegstra, K. (1986) Efficient in vitro import of a cytosolic heat shock protein into pea chloroplasts. Proc. Natl. Acad. Sci. USA 83, 5502-5506

Nakatani, A.J., Barber, J. (1977) An improved method for isolating chloroplasts retaining their outer membranes. Biochim. Biophys. Acta 416, 510-512

Salomon, M., Fischer, K., Flügge, U.-I., Soll, J. (1990) Sequence analysis and protein import studies of an outer chloroplast envelope polypeptide. Proc. Natl. Acad. Sci. USA 87, $5778-5782$

Soll, J. (1987) $\alpha$-Tocopherol and plastoquinone synthesis in chloroplast membranes. Methods Enzymol. 148, 383-392

Soll, J., Berger, V., Bennett, J. (1989) Adenylate effects on protein phosphorylation in the interenvelope lumen of pea chloroplasts. Planta 177, 393-400

Towbin, A., Staehlin, T., Gordon, J. (1979) Electrophoretic transfer of proteins from polyacrylamide gels to nitrocellulose sheets: Procedure and some applications. Proc. Natl. Acad. Sci. USA 76, $4350-4354$

Waegemann, K., Soll, J. (1991) Characterization of the protein import apparatus in isolated outer envelopes of chloroplasts. Plant J. 1, 149-159 